Article

\title{
Pore Structure and Water Transfer in Pietra d'Aspra Limestone: A Neutronographic Study
}

\author{
Luciana Randazzo $^{1}\left(\mathbb{D}\right.$, Giuseppe Paladini $^{2}\left(\mathbb{D}\right.$, Valentina Venuti ${ }^{2, *} \mathbb{C}$, Vincenza Crupi ${ }^{3}$, \\ Frédéric Ott ${ }^{4}$, Giuseppe Montana ${ }^{5}$, Michela Ricca ${ }^{1}{ }^{10}$, Natalia Rovella ${ }^{1}$, \\ Mauro Francesco La Russa ${ }^{1, *}$ and Domenico Majolino ${ }^{2}$ (1) \\ 1 Department of Biology, Ecology and Earth Science, University of Calabria, via Pietro Bucci cubo 12B piano 2, \\ 87036 Arcavacata di Rende (CS), Italy; luciana.randazzo@unical.it (L.R.); michela.ricca@unical.it (M.R.); \\ natalia.rovella@unical.it (N.R.) \\ 2 Department of Mathematical and Computer Sciences, Physical Sciences and Earth Sciences, \\ University of Messina, Viale Ferdinando Stagno D’Alcontres 31, 98166 Messina, Italy; \\ gpaladini@unime.it (G.P.); dmajolino@unime.it (D.M.) \\ 3 Department of Chemical, Biological, Pharmaceutical and Environmental Sciences, University of Messina, \\ Viale Ferdinando Stagno D'Alcontres 31, 98166 Messina, Italy; vcrupi@unime.it \\ 4 Laboratoire Léon Brillouin, CEA Saclay, 91191 Gif-sur-Yvette CEDEX, France; frederic.ott@cea.fr \\ 5 Department of Earth and Sea Sciences (DiSTeM), University of Palermo, Via Archirafi 22, \\ 90123 Palermo, Italy; giuseppe.montana@unipa.it \\ * Correspondence: vvenuti@unime.it (V.V.); mlarussa@unical.it (M.F.L.R.)
}

Received: 1 September 2020; Accepted: 24 September 2020; Published: 26 September 2020

\begin{abstract}
Neutron radiography (NR) was here applied to study the effects of two different commercially available consolidants on the water absorption properties in a particular type of limestone (biocalcarenite), known as Pietra d'Aspra stone, which is one of the most extensively used lithotypes in Sicilian Baroque buildings. Our attention was mainly focused on the evaluation, using a fast and nondestructive visualization of water motion through capillarity, of the effectiveness of such layers as consolidating agents in view of preserving and maintaining both old and modern structures. The biocalcarenite was treated with nanosilica (Nano Estel ${ }^{\circledR}$ ) and nanolime $\left(\right.$ CaLoSil $\left.{ }^{\circledR}\right)$ by brushing it until full saturation, and then artificially weathered by salt crystallization and temperature/relative humidity jumps. Liquid distribution and height of the water front were monitored as a function of time. Significant differences in the water suction behavior among all the investigated samples were highlighted, which allowed us to gain insight into the coating/substrate interaction mechanisms which regulate the fluid mobility inside the porous network of the limestone.
\end{abstract}

Keywords: neutron radiography; porous limestones; consolidants; water kinetics; artificial weathering; capillarity

\section{Introduction}

The presence of water inside the porous matrix of building materials, whether artificial (concretes and mortars) or natural (stones), plays a main role in determining their mechanical performance and stability. As well known, salt crystallization and transportation of unwanted substances through water penetration can lead to the formation of cracks and plane distortions, strongly affecting the structural integrity of the construction itself. Restoration treatments aimed at "conservation" should preserve the original material while slowing down the decay process as much as possible. Stone durability is a term describing how well the material retains its original physical and mechanical properties. As a consequence, it concerns several aspects such as texture, structure, and mineralogical composition, as well as methods of quarrying and handling, applied loads, and environmental conditions to which 
the considered stone has been exposed [1-6]. In particular, during the past few centuries, porous calcareous stones were extensively used as building material in several areas of the Mediterranean basin. In coastal urban environments, after a protracted period of exposure to the atmospheric agents, these lithotypes are very often subjected to extensive crumbling due to soluble salt crystallization in pore spaces [7-13]. Consequently, for this type of natural building material, the relationship among pore structure, water/moisture transport, and salt crystallization has been extensively investigated for understanding the mechanisms and kinetics of degradation processes [2,9,14-19].

In this framework, different consolidant products have been commercialized and used in the last few years in the treatment of building materials of historical monuments, in order to preserve the whole structure and to guarantee a longer durability [20]. The high efficiency and minimum appearance alterations of such consolidating agents represent two highly demanded conditions in the field of conservation science. Both aspects depend on how these products interact with the relative substrates, affecting the penetration depth and the difference in porosity between the consolidant and the underlying bulk stone. In particular, the 3D pore distribution of both the stone and the coating layer represents a crucial parameter since it regulates the fluid mobility inside the material.

Currently, liquid imbibition dynamics can be visualized through different approaches including gamma rays [21,22], nuclear magnetic resonance (NMR) [23], and neutron radiography (NR) [24]. However, it must be pointed out that NR, among the other techniques, represents the best solution for the evaluation of the height of the water front and its 3D distribution, as all hydrogen-rich fluids are characterized by higher neutron attenuation coefficients with respect to elements typically present in limestone specimens. The study of water migration by capillarity in calcite-based materials (such as limestones) by means of NR has gained considerable attention by the scientific community in recent years [25-30]. It has been successfully applied for the study of water movement by spontaneous imbibition in rocks [31-33], sandstones [34,35], concrete [36,37], and bricks [38]. Generally, a linear trend of the height of the water front $(h(t))$ with the square root of the exposure time is attained, according to the Lucas-Washburn (L-W) equation. It is worth nothing that the water rise by capillarity follows the aforementioned classical behavior only for structures characterized by a homogeneously distributed porosity. However, violations in the diffusion-like process can be often achieved [39,40], at the early stage of water contact or after a certain period of time, revealing the occurrence of several processes during the water suction and/or the presence of nonuniform/disordered porosimetry within the inner structure of the investigated sample.

In the present work, neutron radiography was successfully applied in order to quantify, in a nondestructive way, the susceptibility to weathering of a particular type of limestone, i.e., Pietra d'Aspra stone. This variety of biocalcarenite was extensively used in the architectural practice of Palermo (Sicily, Italy) and its surroundings, since antiquity and especially in the second half of the 17th century, for building Baroque palaces, nobiliary villas, and churches [41]. The generalized interest in this type of porous calcareous stone derives from its availability in the territory and from the relative ease of quarrying and workability. Its main forms of deterioration are represented by blackish sulfur-bearing encrustations developed on surfaces protected by rain-washing, or alveolar decohesion and extensive crumbling in the exposed parts of the masonry which are related to the precipitation of soluble salts [42]. On the basis of the intrinsic value and the number of monumental complexes made with Pietra d'Aspra stone, the development of innovative experimental procedures aimed at evaluating performances of consolidating treatments on this specific limestone is considered, at present, of great attraction and relevance.

More specifically, in our case, the interaction mechanisms between two consolidant products, namely, nanosilica $\left(\mathrm{Nano} \mathrm{Estel}^{\circledR}\right.$, nano-SiO $\left.{ }_{2}, \mathrm{NS}\right)$ and nanolime $\left(\mathrm{CaLoSil}{ }^{\circledR}, \mathrm{Ca}(\mathrm{OH})_{2}, \mathrm{NL}\right)$, and the analyzed stone were mainly addressed, with the aim of highlighting the water transport behavior exhibited by the investigated material after consolidation. Treated samples were also exposed to different accelerated weathering tests such as 15 cycles of salt crystallization and temperature/relative humidity jumps, in order to simulate the material's response to different natural stresses. Results 
reported here could be used, in principle, to propose an optimized procedure for preserving and maintaining buildings/objects of interest in the field of cultural heritage and conservation science.

\section{Materials and Methods}

\subsection{Geological Notes and Sampling}

Biocalcarenite outcrops have been intensively quarried in the whole plain of Palermo throughout past centuries [43-45]. These deposits can be regarded as deposits of shallow tidal sea/representing low sea-level sediments over the Tyrrhenian period (Upper Pleistocene, 0.5-0.1 Ma), and they overlie the Mesozoic Carbonatic Formation and/or Numidian Flysch Formation with discordance [46]. This lithotype, locally called Pietra d'Aspra, comes from quarrying districts located a few kilometers west of Palermo. Ancient quarries can still be observed. Different varieties belong to the same calcarenite lithotype, characterized by a different compaction following the deposition, a different carbonate cement percentage, and, consequently, having a different total open porosity, grain distribution, and color. With regard to these parameters, it is possible to distinguish lithotypes with a grain size ranging from medium to fine arenite $(0.5-0.125 \mathrm{~mm})$ and lithotypes with a grain size ranging from coarse to medium arenite $(2-0.5 \mathrm{~mm})$, more or less cemented. In particular, the coarse-grained calcarenite, well cemented and characterized by a high value of compressive strength (30 MPa), can mostly be used for walls and facades such as basements and columns. On the other hand, soft calcarenites were used as decorative materials thanks to their easy workability and low value of compressive strength [45,47].

Representative samples of a coarse-grained calcarenite were chosen for this study. Calcarenite samples were taken from the Guttadauro quarry front located in Via Cotogni, Aspra village, Palermo (Figure 1a,b).
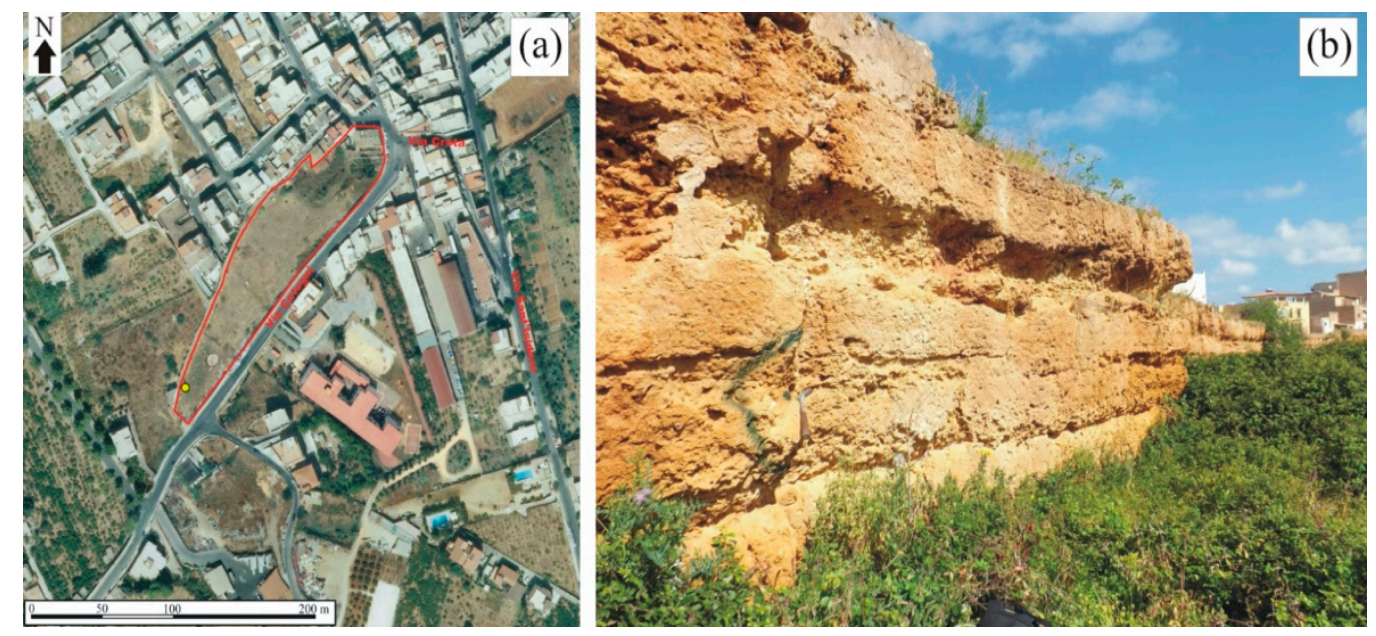

Figure 1. (a) Aerial photo with quarry location (in red the perimeter of the quarry) and sampling point (yellow circle); (b) "Guttadauro" quarry front.

\subsection{Petrographic and Physic-Chemical Analyses}

Minero-petrographic analysis was carried out by thin-section polarized light microscopy (PLM) (Leica DM-LSP) on a representative sample of Pietra d'Aspra, not consolidated and not artificially weathered, allowing the identification of the grain size, composition, cement percentage, and macroporosity. Additionally, the pore-size distribution analysis on a small fragment of the same representative sample was also evaluated via mercury intrusion porosimetry (MIP) (Autopore IV 9500 V1.05, Micromeritics Instruments, applied pressures in the range from subambient to 33,000 psi). Pore radius calculation was carried out using the Washburn equation $(r=-2 \gamma \cos \theta / P$, where $r$ is the pore entry radius in which mercury is intruded, $\gamma$ is the surface tension, and $\theta$ and $P$ represent the contact angle of mercury with the solid and the applied pressure, respectively). After this preliminary 
characterization, samples (dimensions $\sim 5 \times 5 \times 2 \mathrm{~cm}^{3}$ ) were treated with the two commercial products, i.e., Nano Estel ${ }^{\circledR}$ (CTS srl, Vicenza, Italy) and CaLoSiL ${ }^{\circledR}$ (Bresciani srl, Milano, Italy), whose applications were carried out on the surface of each sample by brushing it several times until saturation. After a curing time period of 28 days, accelerated weathering tests ( 15 cycles of salt crystallization and temperature/relative humidity (T/RH) jumps) were carried out on treated and untreated samples (see Table 1), following the procedure reported in [48]. In particular, each cycle of salt crystallization consists of (a) $2 \mathrm{~h}$ of immersion in a supersaturated solution of sodium sulfate $\left(14 \% \mathrm{w} / \mathrm{w}\right.$ at $\left.20^{\circ} \mathrm{C}\right)$ for $10 \%$ of the height, (b) $8 \mathrm{~h}$ of drying in an oven at $45^{\circ} \mathrm{C}$, and (c) $16 \mathrm{~h}$ of cooling at room temperature. Initial and final weights after each cycle were measured for each test sample (in triplicate). The resulting weight loss (average value of three measurements) was, therefore, determined. Lastly, three specimens for each treatment and three specimens for untreated ones underwent a humidity/temperature jump in a climatic chamber after three cycles of salt crystallization with the following conditions: temperature (T) variation between $20^{\circ} \mathrm{C}$ and $45^{\circ} \mathrm{C}$ and relative humidity (RH) variation between $40 \%$ and $80 \%$ for about $1500 \mathrm{~h}$.

Table 1. List of all the investigated specimens together with details about products and experimentation tests. PLM, polarized light microscopy; MIP, mercury intrusion porosimetry; T, temperature; RH, relative humidity.

\begin{tabular}{|c|c|c|c|c|c|}
\hline Sample Code & Products & Experimentation Tests & $\begin{array}{c}\text { Preliminary Characterization } \\
\text { (PLM, MIP) }\end{array}$ & $\begin{array}{c}\text { Weight Loss } \\
\text { Measurements }\end{array}$ & $\begin{array}{c}\text { Neutron Radiography } \\
\text { Analysis }\end{array}$ \\
\hline & & & \multicolumn{3}{|c|}{ Performed Analysis (Number of Test Specimens Used) } \\
\hline PA1 & Nano Estel ${ }^{\circledR}$ & $\begin{array}{c}\text { Climatic chamber }(\mathrm{T} / \mathrm{RH}) \text { after } 3 \\
\text { cycles of salt crystallization }\end{array}$ & - & $\times(3)$ & $\times(1)$ \\
\hline PA2 & Nano Estel ${ }^{\circledR}$ & Salt weathering ( 15 cycles) & - & $\times(3)$ & $\times(1)$ \\
\hline PA3 & Nano Estel ${ }^{\circledR}$ & Not weathered & - & - & $\times(1)$ \\
\hline PA5 & $\mathrm{CaLoSiL}^{\circledR}$ & Salt weathering ( 15 cycles) & - & $\times(3)$ & $\times(1)$ \\
\hline PA6 & $\mathrm{CaLoSiL}^{\circledR}$ & Not weathered & - & - & $\times(1)$ \\
\hline PA-TQ & Untreated & Not weathered & $\times(1)$ & - & $\times(1)$ \\
\hline PA-TQ1 & Untreated & $\begin{array}{c}\text { Climatic chamber (T/RH) after } 3 \\
\text { cycles of salt crystallization }\end{array}$ & - & $\times(3)$ & - \\
\hline
\end{tabular}

After salt weathering and T/RH jumps, a preliminary evaluation of the consolidating action of such coatings was achieved by comparing the weight loss in treated and untreated specimens through standard laboratory-based methodologies.

\subsection{Neutron Radiography Analysis}

One test specimen for seven samples (see Table 1) was used for neutron radiography analysis.

Neutron radiographs were collected at the cold neutron imaging spectrometer IMAGINE of the Laboratoire Léon Brillouin (LLB) at the Orphée Reactor, in Saclay (F). By increasing the $L / D$ ratio (with $L$ equal to the distance between the entrance aperture of the neutron beam and the image plane $(400 \mathrm{~cm})$ and $D$ equal to the diameter of the collimator aperture $(1 \mathrm{~cm}))$ up to 400 , absorption contrast values with high resolution $(\sim 0.1 \%)$ were achieved, providing a spatial resolution of about $250 \mu \mathrm{m}$. The incoming beam, characterized by a wide spectrum of neutrons having wavelength between 3 and $20 \AA$, was of $\sim 2 \times 10^{7}$ neutrons $\cdot \mathrm{cm}^{-2} \cdot \mathrm{s}^{-1}$. Finally, for our measurements, the sample-detector distance was $10 \mathrm{~cm}$.

A sCMOS (scientific Complementary Metal-Oxide-Semiconductor) ANDOR NEO camera coupled to a Canon EFS 60mm F/2.8 Macro USM (Ultrasonic Motor) was used to collect the transmitted beam coming from the sample. The key elemental composition of the investigated limestones, mostly characterized by $\mathrm{C}, \mathrm{O}, \mathrm{Ca}$, etc., whose neutron cross-sections are typically two order of magnitudes lower than that of hydrogens $(\mathrm{H})$ in liquid media, allows easily following the water motion by 
spontaneous imbibition. As a result, even for a low quantity of penetrated water, a good contrast between the solid and liquid phase can be observed.

The obtained raw images were corrected using dark-field $\left(I_{(d f)}\right)$ and open-beam $\left(I_{(o b)}\right)$ images taken prior to the sample measurements.

Investigated limestones were contained one by one within an aluminum holder and placed onto a $10 \mathrm{~mm}$ thickness filter paper pack (Kaltek S.r.l. Padova Italy), in order to scan the entire volume. The dynamics of water suction by capillarity was recorded by stepwise manual addition of water into the aluminum basement, which ensured the saturation of the filter paper pack (Scheme 1).

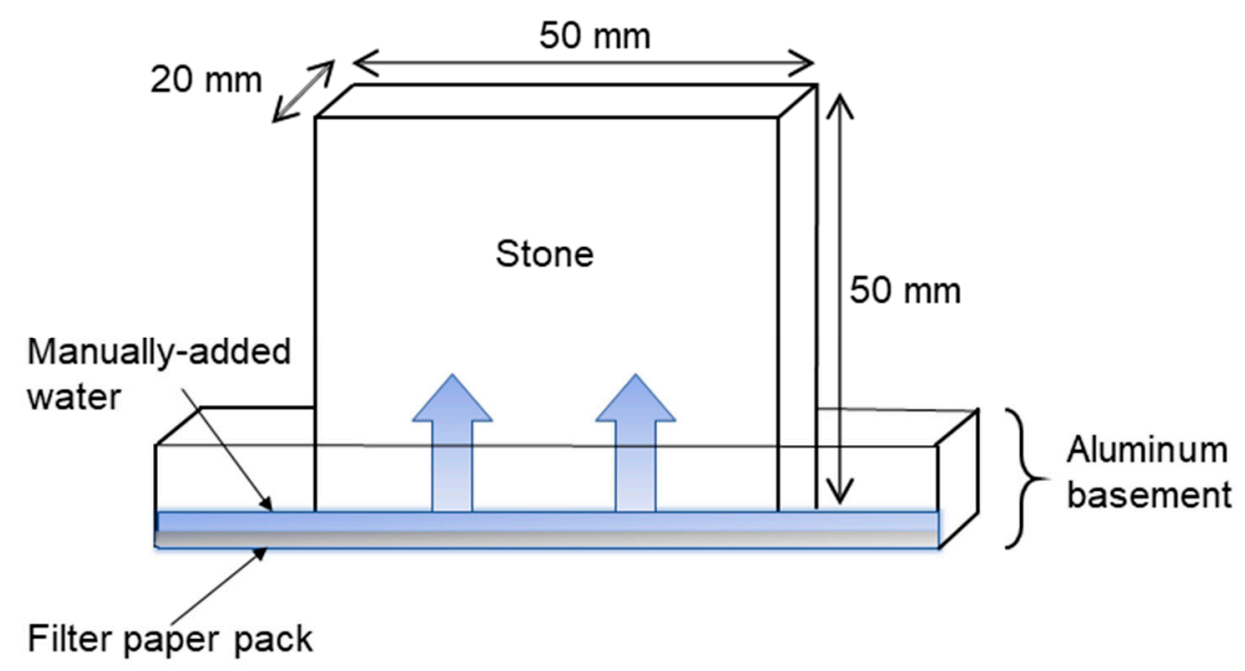

Scheme 1. Graphical representation of the position of the sample, manually added water, and filter paper pack in the aluminum basement.

For each sample, images were recorded with an exposure time of $40 \mathrm{~s}$, until full saturation, except for PA4, for which an exposure time of $10 \mathrm{~s}$ was used. In those cases, in which the saturated condition was not completely reached, measurements were collected for no longer than $\sim 20 \mathrm{~h}$.

A homemade macro of the IMAGINE beamline was used to pre- and post-process raw images. Accordingly, neutron radiographs of the dry $\left(I_{(d)}\right)$ and wet $\left(I_{(w)}\right)$ stone were corrected to both $I_{(d f)}$ and $I_{(o b)}$ using the following relationships:

$$
\begin{aligned}
& I_{(w, c o r r)}=C \frac{I_{(w)}-I_{(d f)}}{I_{(o b)}-I_{(d f)}}, \\
& I_{(d, c o r r)}=C \frac{I_{(d)}-I_{(d f)}}{I_{(o b)}-I_{(d f)}},
\end{aligned}
$$

where $C$ is a rescaling factor accounting for the neutron beam fluctuations. The removal of unwanted bright pixels coming from scattered $\gamma$-rays was achieved by encountering the obtained images through a median filter. The procedure adopted to follow the water content from transmission radiographs consisted of normalizing wet images with respect to dry ones taken prior to the manual addition of water into the aluminum basement. In this way, the contribution of the stone is removed, and the obtained transmitted intensity can be directly related to the amount of water within the stone [32]. However, in order to get quantitative information on the amount of water contained within the material, a calibration of the collected neutron transmission values was necessary. Accordingly, a staircase-like sample holder, containing 12 different water contents with standardized thickness (ranging from $0.09 \mathrm{~mm}$ up to $5.00 \mathrm{~mm}$ ), was used to evaluate the neutron transmission vs. water thickness plot. The obtained calibration curve (see Figure 2) follows a logarithmic behavior in the whole range of standardized water thickness used. From the fitting procedure, the value of the water attenuation 
coefficient was achieved and then used to correctly evaluate the amount of absorbed water within the structure of the investigated limestones, for all the water absorption images.

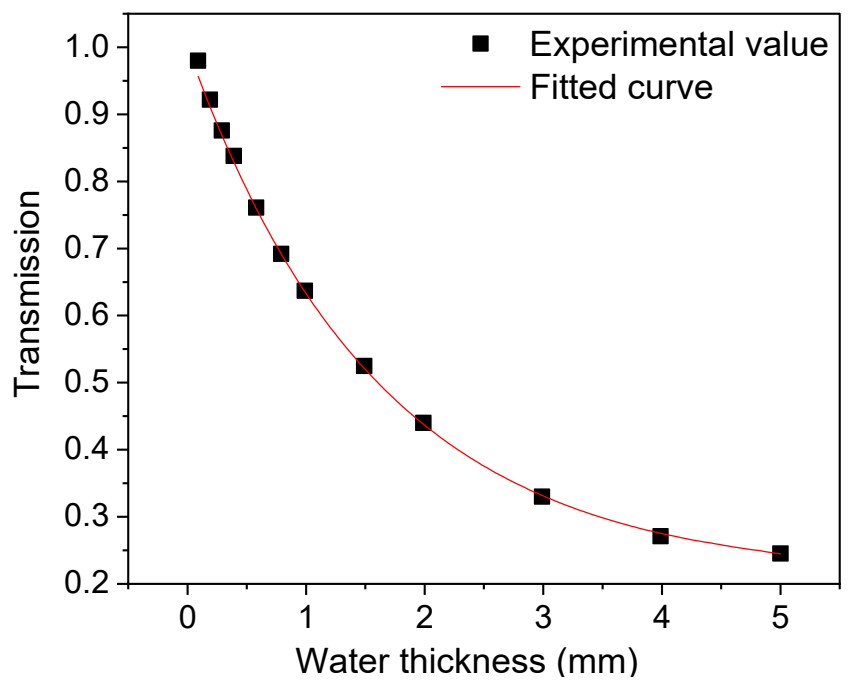

Figure 2. Calibration curve for water transmission values using different water contents with standardized thickness.

The analysis of the neutron radiographs was carried out using the Fiji ImageJ software (Fiji is just ImageJ, Image Processing and Analysis in Java, open source), Version 1.53a, National Institutes of Health and Laboratory for Optical and Computational Instrumentation (University of Wisconsin), Madison, WI, US [49]. Following the procedure described by Kim et al. [50], the water content distribution was computed by dividing the obtained wet image $\left(I_{(w, c o r r}\right)$ by the corresponding dry one $\left(I_{(d, c o r r)}\right)$; then, the 2D distribution of the water thickness $\left(\theta_{w}(x, y)\right)$ could be calculated as follows:

$$
\theta_{w}(x, y)=-\frac{\ln \left[\frac{I_{(w, c o r r)}(x, y)}{I_{(d, c o r r)}(x, y)}\right]}{\mu_{w}},
$$

where $I_{(w, c o r r)}(x, y)=I_{0}(x, y) e^{-\left(\mu_{s} \theta_{s}+\mu_{w w} \theta_{w}\right)}$ and $I_{(d, c o r r)}(x, y)=I_{0}(x, y) e^{-\mu_{s} \theta_{s}}$, in which $I_{0}(x, y)$ indicates the intensity of the incoming neutron beam, $\mu_{s}$ and $\mu_{w}$ are the stone and water attenuation coefficients, and $\theta_{s}$ and $\theta_{w}$ are the thickness of the stone and the equivalent water thickness.

Since the thickness of the stone is known, the mean moisture content (MC) was firstly evaluated as

$$
M C=\frac{\theta_{w} \cdot \rho_{w}}{\theta_{s}},
$$

where $\rho_{w}$ represents the density of water. Then, by dividing the MC by the density of the stone $\rho_{s}$, the water content (WC), expressed as a weight percentage (\%), could be easily calculated as

$$
W C=\frac{M C}{\rho_{s}} .
$$

As the investigated stone was mostly composed of calcite ( $90 \%$ of $\left.\mathrm{CaCO}_{3}\right), \rho_{s}$ was taken to be almost equal to $2.69 \mathrm{~g} / \mathrm{cm}^{3}$. 


\section{Results and Discussion}

\subsection{Petrographic and Physicochemical Analysis}

Pietra d'Aspra can be classified as a grainstone [51] or biosparite [52]. The grain size distribution is quite heterogeneous (Figure 3a) and it is composed of at least two secondary modes, one of them being coarse-grained sand. The principal components are calcareous bioclasts, including fragments of molluscan shells, bryozoans, echinoderms, corals, and foraminifera sized up to 1-1.5 mm (Figure 3b).
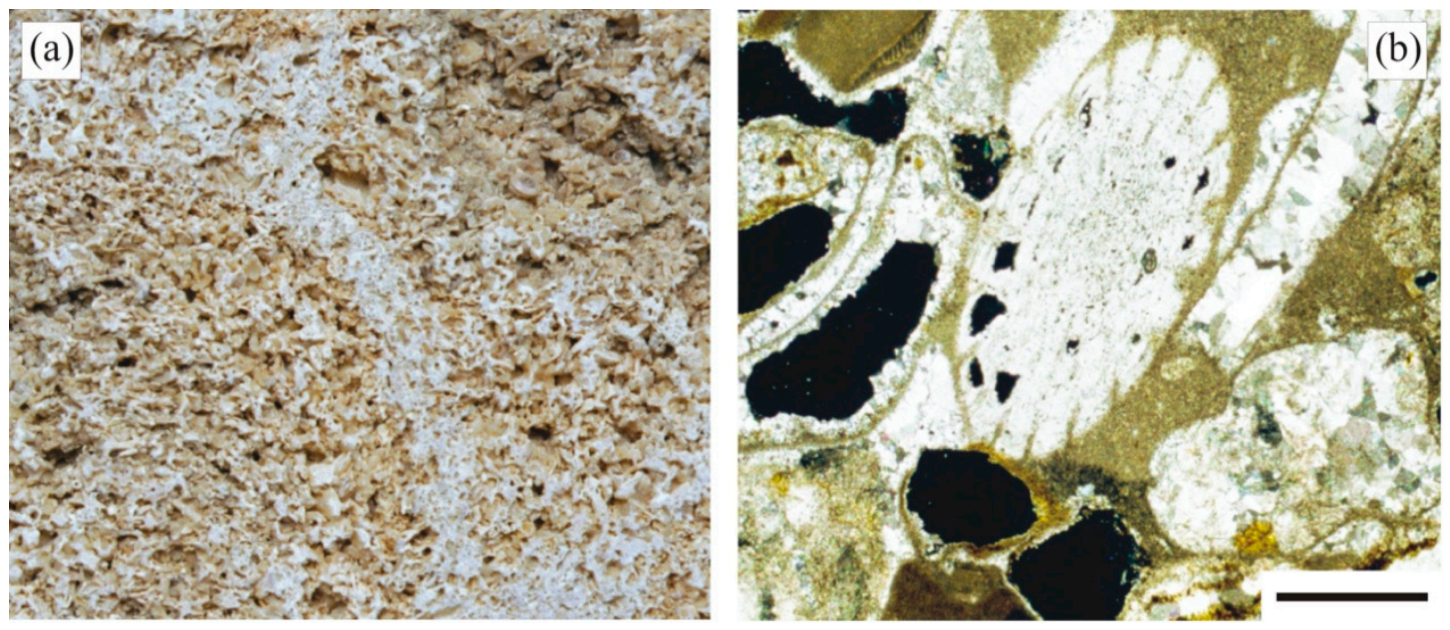

Figure 3. (a) Fresh cut surface of a representative specimen of Pietra d'Aspra (not consolidated and not weathered, sample PA-TQ); (b) thin-section microphotograph of the same sample (scale bar = $0.5 \mathrm{~mm}$ ).

The most abundant accessory components are lithic fragments ( $0.1 \mathrm{~mm}$ in size), possibly derived from Mesozoic limestones and dolostones, and monocrystalline quartz grains ranging from 0.04 to $0.2 \mathrm{~mm}$ in size. More sporadically, clasts of siliceous rocks (quartzarenites and radiolarites) may occur. The micrite syngenetic matrix is, in general, poorly abundant, while different types of diagenetic carbonate cements have been reported, such as "meniscus" and "dog teeth". Predominantly intergranular macroporosity with cavities having a variable and irregular shape, ranging in size from 0.2 to $5 \mathrm{~mm}$, has also been highlighted. Table 2 summarizes most petrographic and mineralogical characteristics of this stone together with the main physical parameters [53].

Table 2. List of petrographic, mineralogical, and physical characteristics of Pietra d'Aspra samples.

\begin{tabular}{|c|c|c|c|c|c|c|c|}
\hline $\begin{array}{l}\text { Classification } \\
\text { (Dunham/Folk) }\end{array}$ & $\begin{array}{c}\text { Mean Grain } \\
\text { Size }(\mathrm{mm})\end{array}$ & $\begin{array}{l}\text { Colour } \\
\text { (Munsell) }\end{array}$ & * Calcite & * Quartz & * Dolomite & $\begin{array}{l}{ }^{*} \text { HCl-Insoluble } \\
\text { Residue (W\%) }\end{array}$ & ${ }^{*} \rho_{\mathrm{s}}$ \\
\hline $\mathrm{BS} / \mathrm{G}$ & 2.4 & 10YR 7/6 & $97 \%$ & $2 \%$ & $1 \%$ & 5 & 2.69 \\
\hline$* \mathrm{SiO}_{2}$ & $* \mathrm{TiO}_{2}$ & ${ }^{*} \mathrm{Al}_{2} \mathrm{O}_{3}$ & ${ }^{*} \mathrm{Fe}_{2} \mathrm{O}_{3}$ & ${ }^{*} \mathrm{MnO}$ & ${ }^{*} \mathrm{MgO}$ & ${ }^{*} \mathrm{CaO}$ & \\
\hline $2.16 \%$ & $0.03 \%$ & $0.55 \%$ & $0.52 \%$ & $0.09 \%$ & $0.78 \%$ & $52.54 \%$ & \\
\hline${ }^{*} \mathrm{Na}_{2} \mathrm{O}$ & ${ }^{*} \mathrm{~K}_{2} \mathrm{O}$ & ${ }^{*} \mathrm{P}_{2} \mathrm{O}_{5}$ & * Sr & $* \mathrm{Zr}$ & ${ }^{*} \mathrm{Ba}$ & ${ }^{*} \mathrm{LOI}$ & \\
\hline$<0.01 \%$ & $0.05 \%$ & $0.05 \%$ & 312 ppm & $2 \mathrm{ppm}$ & $15 \mathrm{ppm}$ & $43.23 \%$ & \\
\hline
\end{tabular}

Legend: $\mathrm{BS}=$ biosparite; $\mathrm{G}=$ grainstone; $\rho_{\mathrm{s}}=$ density of the stone $\left(\mathrm{g} / \mathrm{cm}^{3}\right)$. ${ }^{*}$ Data sourced from [53].

As well known, mercury intrusion porosimetry does not allow determining the total volume of the stone; nevertheless, porosimetric curves give useful information about pore size distribution in the range of $200 \mu \mathrm{m}-0.1 \mu \mathrm{m}$. The evaluation of the pore range, influencing the water uptake of the calcarenite, is an important factor to understand water transport properties.

Grain size, grain packing, and grain contact usually control pore shape and pore size and, therefore, determine the physical properties related to water transport and storage. Pore shape seems to be of primary importance in the relationship between dynamic and static moduli of elasticity and strength. 
It appears that textural properties may represent the key parameters controlling physicomechanical properties and weathering behavior.

The porosimetric curve obtained for the PA-TQ sample (not consolidated and not weathered) reveals that the investigated calcarenite has an important porosity and a very wide range of pore sizes (Figure 4), highlighting the heterogeneity of pore network systems in these types of rocks. This characteristic depends on the differences in grain size and cementation degree. The pore network system is addressed in the migration of water solutions, even if the role of each dimensional range in the capillary transfer is dependent on the pore's size, shape, and connectivity. The sample is characterized by a bimodal pore network system in which the transfer of water solutions occurs heterogeneously.

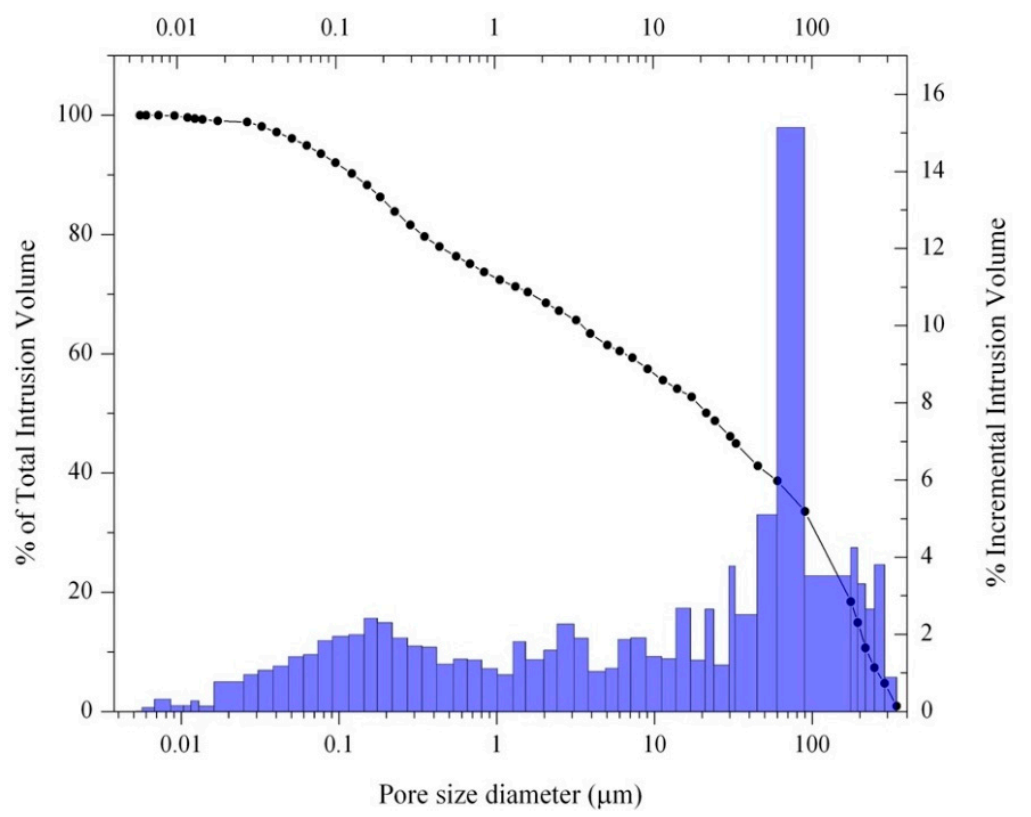

Figure 4. Pore size distribution curve of a representative specimen of Pietra d'Aspra (not consolidated and not weathered, sample PA-TQ). Left $y$-axis $=\%$ of total intrusion volume (line); right $y$-axis $=\%$ of incremental intrusion volume (bars).

Degradation forms, such as alveolization and differential erosion, develop more easily in the varieties of rocks with such a heterogeneous porous network. This heterogeneity makes difficult the migration of the saline solutions through the porous capillary network, mainly because of the poor connection between the pores. A slowdown in the transfer kinetics of the aqueous solutions toward the external surface occurs, determining a retreat of the evaporation front toward the inside of the rock. In these areas, the salts can crystallize and concentrate, causing the granular disaggregation of the rock structure.

After the salt crystallization test, the weight variations of consolidated (PA2 and PA5) and untreated specimens (PA-TQ2) were measured (Figure 5a). A great number of efflorescences, due to the transfer of the salt solution, are more evident on the surface of untreated sample with respect to the consolidated ones. In fact, the presence of the consolidants seems to affect the evaporation rate of the solution at the surface of the stone. The development of efflorescence and subefflorescence leads to an increase in weight of the individual samples, which seems to balance the slight loss of material suffered by the specimens. This behavior is not dependent on the type of used consolidant, although minor variations occurred in the specimens treated with NS. After 15 cycles, a slight smoothing of the edges was highlighted in all the specimens, especially in the unconsolidated ones, followed by the samples treated with the NL product. For what concerns consolidated specimens subjected to humidity changes along with temperature fluctuations (PA1 and PA4), the weight variations were also recorded during the first three cycles of salt crystallization and at the end of the stay inside the climatic chamber 
( 60 days), and they were finally compared with those of untreated samples (PA-TQ1). Figure $5 \mathrm{~b}$ shows that the greatest weight gain occurs for the samples treated with NL, indicating that specimens became heavier from salt precipitation compared to both the untreated and the NS-treated ones. However, none of the rock samples showed obvious cracks, flaking, or loss of material, even at the end of the experiment, meaning that the damage induced by subsequent changes in temperature and humidity seems to be rather weak.
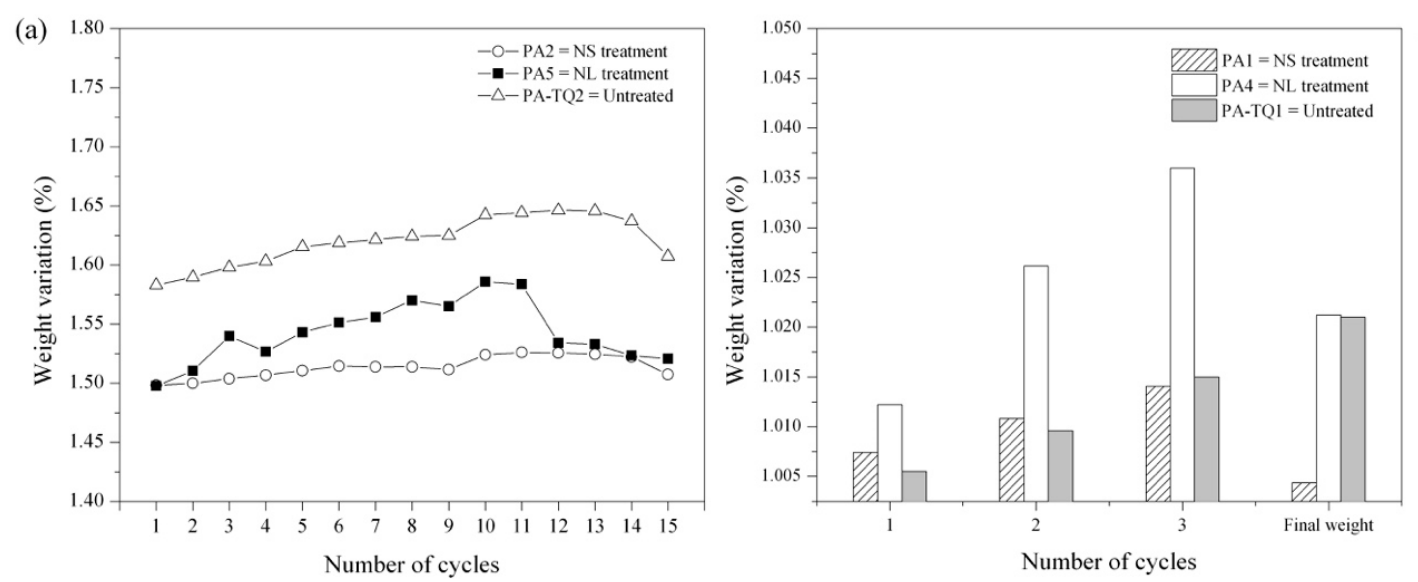

(b)

Figure 5. Weight variation (\%) (a) after salt crystallization test and (b) after temperature/relative humidity jumps.

\subsection{Neutron Radiography Analysis}

Time-lapsed radiographs of water capillary suction collected for PA1 sample at nine different selected time-steps are displayed in Figure 6, as an example.
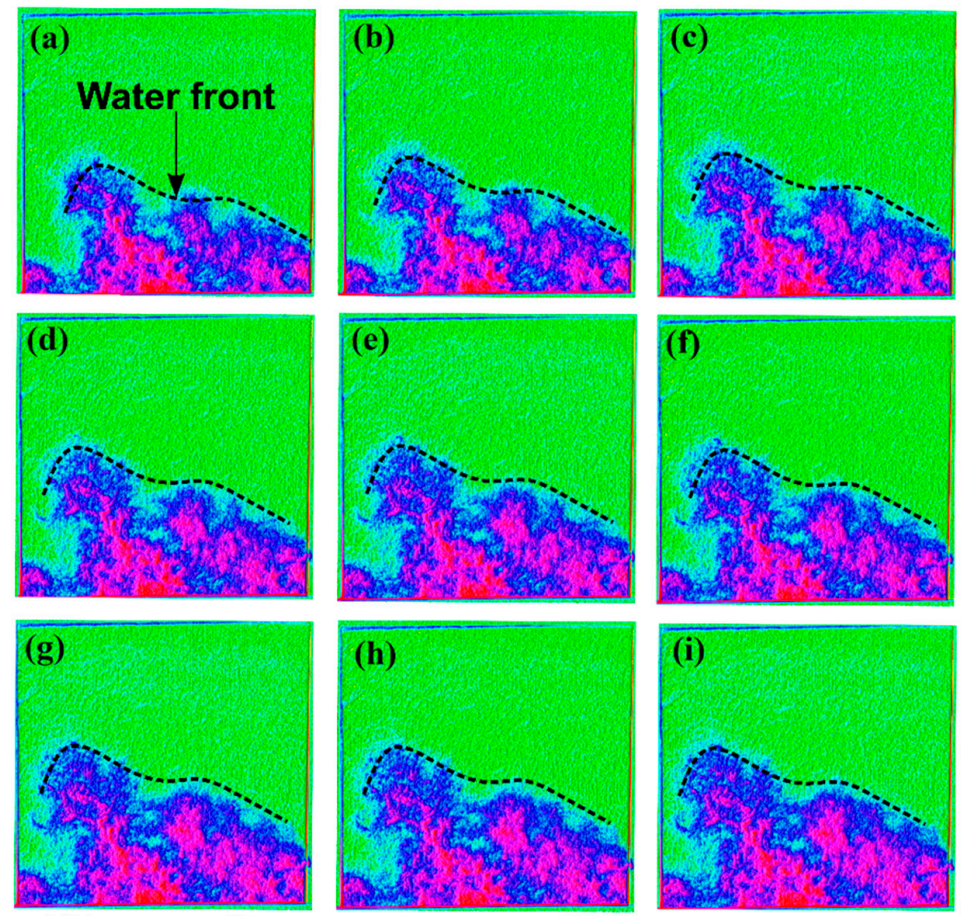

Figure 6. False-colored transmission images of water imbibition in PA1 sample at (a) $40 \mathrm{~s}$, (b) $2560 \mathrm{~s}$, (c) $3840 \mathrm{~s}$, (d) $5120 \mathrm{~s},\left(\right.$ e) $6400 \mathrm{~s},\left(\right.$ f) $7680 \mathrm{~s},\left(\right.$ g) $8960 \mathrm{~s}$, (h) 10,240 s, and (i) 11,560 s. In green, the $5 \times 5 \mathrm{~cm}^{2}$ surface area of the limestone is displayed, whereas the blue/purple/red regions account for the liquid phase characterized by an ever-increasing amount of water. The quantitative evaluation of the water content is addressed from the analysis of the wetting profiles (see text for details). 
A first inspection of Figure 6 reveals how the water rising in PA1, as for the majority of the investigated samples, is characterized by an extremely fast "rate" of spontaneous imbibition during the first stage of the absorption test, followed by a slow dynamic. This evidence, together with a nonuniform distribution of water during the uptake process, supports the well-known heterogeneity and poor interpore connectivity of the analyzed stone, as also revealed by the pore size distribution analysis (see Figure 4). This result can be considered, in a way, experimental evidence of the effect that the bimodal distribution of porosity in Pietra d'Aspra limestone exerts on the water transfer behavior. In fact, as the stone is not uniform whether in terms of porosity or in terms of the size of the individual natural components (i.e., calcareous bioclasts and lithic fragments), a regular rise, as observed in a large variety of similar systems [54], was not expected. Furthermore, as the water kinetics shown in Figure 6 is descriptive of the PA1 sample, consolidated and subjected to a climatic chamber, a difficulty in the migration of saline solutions through the capillary porous lattice can be hypothesized. As a result, salts may shrink and crystallize, leading to a partial granular stone disaggregation. However, as we see later in the text, the presence of nano- $\mathrm{SiO}_{2}$ brushed onto the limestone surface strongly reduces the amount of water (wt.\%) within the stone network with respect to that observed for the reference sample (PA-TQ), proving a remarkable effectiveness of such a coating as a consolidating agent against accelerated weathering tests. Moreover, after a time interval of $\sim 2600 \mathrm{~s}$, a slight formation of salt efflorescence can be detected as a blue spot that stretches out over the lateral surface of the stone in the bottom-right area of each image (except for Figure 6a). This evidence reveals the development of a preferential pathway for the liquid water during the imbibition toward the right-lateral surface of the stone, which spilled out after about $2600 \mathrm{~s}$.

In order to provide a quantitative picture of the effects that consolidants exert on the behavior of the water suction through capillarity in our investigated materials, in Figure 7, typical plots of water content (WC) as a function of the sample height are displayed.

A first inspection of Figure 7 reveals that, for all the investigated samples, enhanced water penetration during the first stage of water contact is achieved, as suggested by the diminishing of the distances between two consecutive curves as time increases. This phenomenon can be associated with the presence of diagenetic cement, which slows the absorption process, in conjunction with a progressively diminishing of the "free" space available for water upon approaching the top of the material.

Concerning the reference sample (PA-TQ), the obtained values of water content and height were found to be equal to $\sim 3 \mathrm{wt} . \%$ and $\sim 50 \mathrm{~mm}$, respectively. These values are always higher than or comparable to (except for the water content in PA4) those obtained for all the treated and artificially weathered stones, revealing (i) experimental evidence of the interaction between the coating and the substrate, and (ii) the presence of fractures and distortions as a result of microclimatic stimuli and salt crystallization. This occurrence, however, can be considered as proof of the consolidating action of both used products. More in detail, as evidenced by the height reached by water during the first 13,310 s of suction, samples treated with nano- $\mathrm{SiO}_{2}$ (NS) show higher performances with respect to those treated with nanolime (NL). In fact, whereas, in samples PA4, PA5, and PA6 (NL-treated), values of water height and content similar to those observed for the reference sample (PA-TQ) were obtained, in PA1, PA2, and PA3 (NS-treated), the water height reached $\sim 20, \sim 15$ and $\sim 30 \mathrm{~mm}$, respectively, showing a hindering in the water uptake of $\sim 60 \%$. In this case, it is reasonable to assume that the presence of a millimeter-thick layer of NS brushed onto the limestone surface leads to an extensive occlusion of the outer pores, preventing the penetration of water inside the stone network. On the other hand, we can state that the presence of NL, as also occurs in the reference (PA-TQ) specimen, allows the pore network to "breathe", resulting in a faster water suction kinetics. It is worth remarking that if, on one hand, the almost total obstruction of pores represents a suitable condition in order to avoid the introduction of external unwanted substances through liquid inclusion, on the other hand, an almost open structure, as that resulting from the application of $\mathrm{NL}$, may reduce the risk of formation of cracks and fractures originating from the development of high crystallization pressures. 

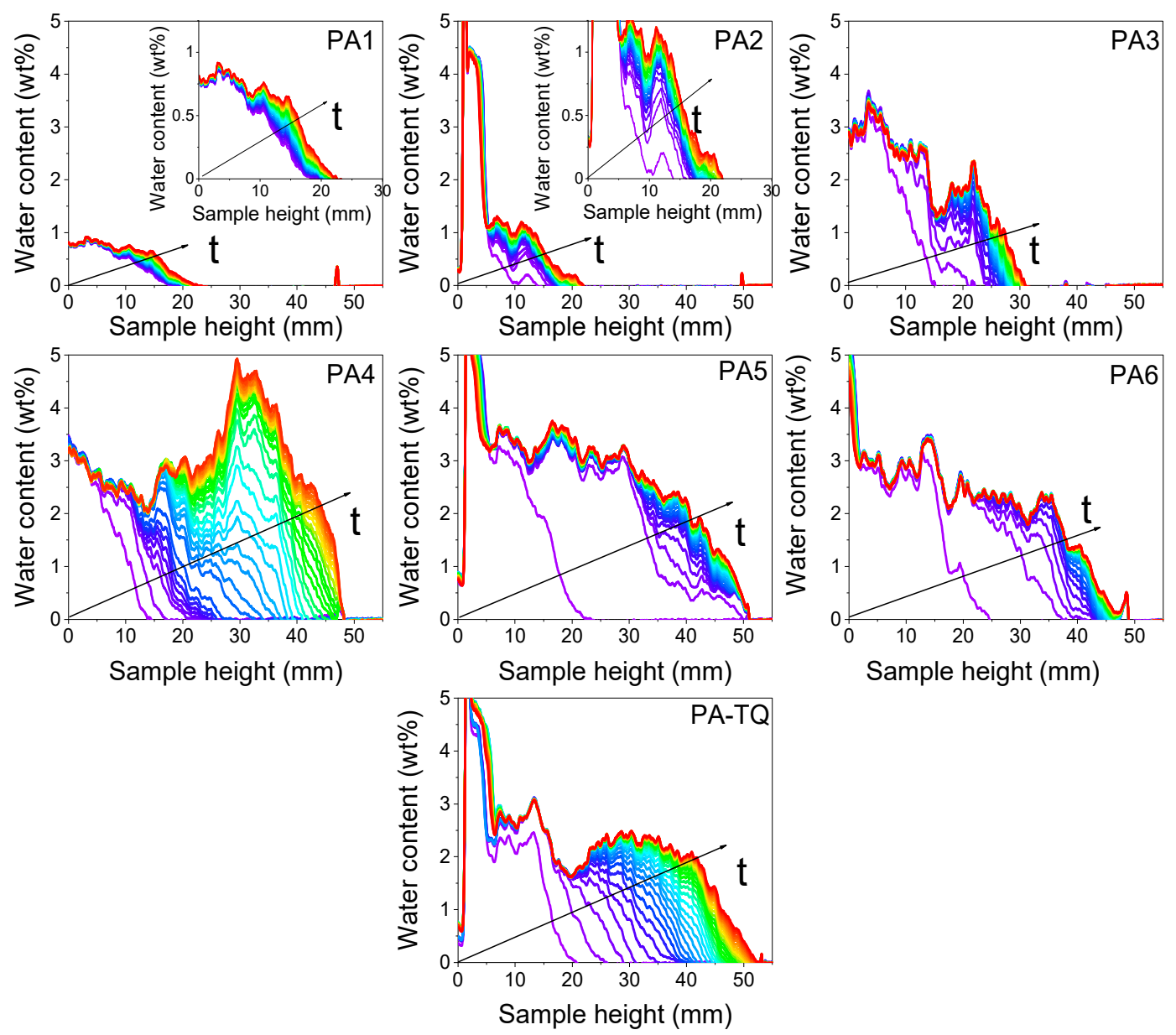

Figure 7. Water content profiles vs. sample height as obtained following the procedure described in Section 2.3. As already stated, neutron radiographs were collected every $40 \mathrm{~s}$ for all samples except for PA4, for which a time-step of $10 \mathrm{~s}$ was used. In our case, sample PA4 was measured for a total of $13,310 \mathrm{~s}$, during which a water-saturated condition was achieved. For all the other samples, longer exposure times were necessary, since a slower water imbibition rate was observed after the initial stage of exposure with the water bath. For this reason, the water content profiles reported here were collected in the first $\sim 13,310 \mathrm{~s}(3.7 \mathrm{~h})$ of contact for comparison.

Let us focus our attention on the effect that the artificial weathering exerts on the water absorption behavior in our samples. Concerning samples exposed to thermal and RH stresses, namely, PA1 and PA4, a significant difference in the amount of absorbed water can be clearly observed. In fact, whereas, in PA4, the WC value was found to be equal to $\sim 3 \%$ (with a strong increase to $\sim 5 \%$ between $\sim 25$ and $\sim 35 \mathrm{~mm}$ ), in PA1, WC is remarkably reduced, reaching approximatively $\sim 0.8 \%$. It is well known that the majority of the structural alteration induced by thermal/RH stresses in porous materials, in terms of both pore size distribution and degree of connection, must be ascribed to the thenardite-mirabilite phase transition [55]. As a consequence, an expansion of the initial microcracks of the stone should be expected, leading to visible alteration in the water absorption properties with respect to the reference sample. However, in the case of PA1, the presence of NS results in an overall diminishing of the water absorption tendency of the material, also limiting the effect on the pore network induced by artificial microclimatic stimuli. On the other hand, since NL does not occlude pores with the same efficiency as NS, the effect of thermal/RH stresses on the structure is more pronounced, as can be seen from the different "trend" of the corresponding water content profiles, with respect to those calculated in $\mathrm{PA}-\mathrm{TQ}$, as well as the mean water content values. More in detail, whereas, in PA-TQ, the presence of sharp "peaks" (especially between $\sim 20$ and $\sim 50 \mathrm{~mm}$ ) ascribed to a local increase in water content is 
observed, in PA4, a slight enlargement of such features can be recognized (see Figure 7). In the case of PA-TQ, the sharp jagged profiles reasonably reflect the natural pore size heterogeneity of the Pietra $d^{\prime}$ Aspra limestone, as extensively evidenced by the analysis of the pore distribution (see Figure 4). On the other hand, the observed broadening of the localized WC peaks in PA4 suggests the presence of larger cavities/pores as a consequence of the thermally activated thenardite-mirabilite phase transition. As a result, the presence of slightly larger water-filled areas is expected, resulting in the observation of neutron radiographs characterized by extended water-rich domains. It is worth noting that the changes in pore dimensions as a consequence of the aforementioned phase transition are relatively small. However, as can be seen in Figure 8, where the comparison between the WC profiles in PA-TQ and PA4 is reported, the high spatial accuracy achieved by neutron radiography, in terms of liquid distribution within the stone network, allowed us to hypothesize such structural variations otherwise impossible to be highlighted through laboratory-based methodologies.

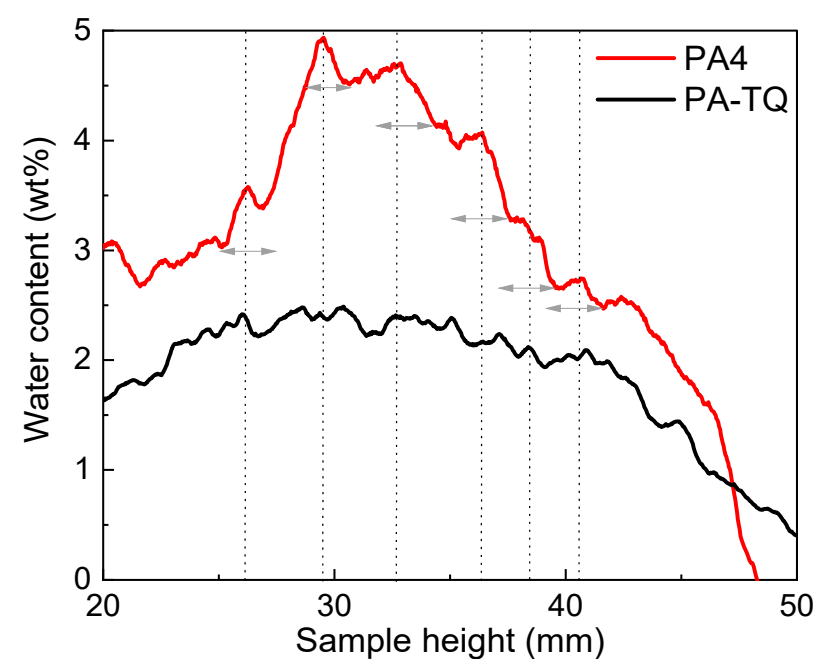

Figure 8. Water content profiles for samples PA4 (NL consolidated) and PA-TQ (reference) between 20 and $50 \mathrm{~mm}$. Dotted lines mark peaks which reveal, better than others, the enlargement induced by the thenardite-mirabilite phase transition activated by microclimatic stimuli (T/RH jumps).

Finally, the relatively high WC value $(\sim 4-5 \%)$ between $\sim 25$ and $\sim 35 \mathrm{~mm}$ in PA4 was probably due to an extended fracture already present inside the stone or caused by the development of high crystallization pressures.

As far as PA2 and PA5 are concerned, accounting for samples exposed to 15 cycles of salt crystallization, a substantial reduction in the amount of absorbed water can also be detected. In PA2, WC was found to be equal to $1 \mathrm{wt} . \%$ after $3.7 \mathrm{~h}$, reaching approximately $18-20 \mathrm{~mm}$. On the contrary, a remarkable increase in WC can be observed in PA5, with a mean value around 3-3.5\%. This occurrence, in agreement with what was already observed in the case of PA1 and PA4 samples, supports the hypothesis that NS, more than NL, clearly enhances the structural properties of the analyzed stone by improving its overall hydrophobicity.

Salt crystallization cycles may lead to the formation of fractures and plane distortions to a major extent with respect to those induced by thermal/RH stresses. Accordingly, liquid solutions penetrate more efficiently and faster thanks to the presence of new "channels", making the structure more susceptible to the presence of water even for short exposure times. In fact, by comparing the WC profiles of PA5 and PA-TQ, at equal contact times, we found that the mean water content value (wt.\%) is always greater in PA5 than in PA-TQ. This occurrence suggests a scenario according to which the new artificially induced cracks in PA5, after 15 cycles of salt crystallization, are now filled with water through spontaneous imbibition, resulting in a higher WC value $(\sim 3.5 \%)$ with respect to that of PA-TQ $(\sim 2.5 \%)$. This hypothesis is also supported by the fact that, in PA6 (sample treated with nanolime 
and not subjected to any accelerated weathering tests), the water content is slightly lower $(\sim 2.5 \%)$ with respect to PA5, suggesting that the main reason for the observed increase in WC in PA5 must be ascribed to the salt crystallization test. NL, in this case, does not affect the limestone almost at all. In the case of PA1, the NS consolidant reduces the access of water through the occlusion of the outer shell pores, reducing the amount of included water and slowing the water dynamics with respect to both PA5 and reference (PA-TQ).

To further investigate the effects of the application of consolidants onto the limestone surface, the mean penetration depth of water $(h)$ was evaluated as the sample height associated with the inflexion point (IP) of the decreasing WC profiles depicted in Figure 7.

IP can be considered as the position from the bottom of the sample at which a water-rich/dry zone transition occurs, and it is, hence, equivalent to the "front" of the wetted region during the capillary suction process. It is worth noting that an exact determination of IPs starting from neutron radiographs can be carried out easily only in those cases in which a uniform capillary absorption occurs, as observed in a large variety of porous materials characterized by a homogeneously distributed porosity $[56,57]$. In our case, however, the intrinsic heterogeneities, in terms of both natural constituents and pore size distribution, make the WC profiles not uniform; consequently, the evaluation of the IPs difficult to carry out. On the basis of these considerations, the IPs of the decreasing curves reported in Figure 7 and, hence, the position of the wetting front were approximated to the points corresponding to half of the maximum water content values, which are different in each investigated sample [58].

From a theoretical point of view, the behavior of $h$ as a function of time can be predicted by using the analytical Lucas-Washburn (L-W) equation (Equation (6)) $[59,60]$.

$$
h(t)=K \sqrt{t}
$$

where $K$ is a coefficient, known as sorptivity $\left(\mathrm{m} / \mathrm{s}^{0.5}\right)$, accounting for the tendency of a porous material to absorb/transmit liquid through natural imbibition. Generally, the L-W model assumes not only a complete saturation of the region behind the wetted front, but also a uniform pore size distribution of the material. Consequently, in materials characterized by a broad distribution of pores sizes, as in our case, deviation from the aforementioned model is often achieved. Nevertheless, by looking at the way in which the experimental values diverge from the expected ones, several considerations can still be made. In Figure 9, we report the $h(t)$ vs. $\sqrt{t}$ plot for all the investigated PA samples in the $0-13,310 \mathrm{~s}$ time range.

The comparison of the $h(t)$ vs. $\sqrt{t}$ plots for the PA-TQ specimen with those calculated for the treated limestones not subjected to any artificial weathering test (PA3 and PA6) indicates that the impregnation of the stone surface with NS visibly modifies the water transfer properties of the limestone to a major extent compared to the treatment with NL, both at the early and, mostly, at the late stage of the absorption test. This was also qualitatively confirmed by the extremely slow water kinetics observed in PA1, PA2, and PA3 with respect to that observed in PA4, PA5, and PA6.

The observed trends of $h(t)$ vs. $\sqrt{t}$ strongly deviate from the L-W model, especially for $\sqrt{t}>\sim 30 \mathrm{~s}^{0.5}$, indicating a heterogeneity of the porous medium in which the capillary rise of water is due to the contribution of several pore families with different size distribution. Nevertheless, below $\sqrt{t} \sim 30 \mathrm{~s}^{0.5}$, a diffusion-like behavior, as that predicted by the L-W model, can be reasonably hypothesized. This evidence can be justified thinking that, in the early stage of the test, the water motion is affected by the presence of a pore's distribution influenced by both the stone and the consolidating agents, limited to the penetrated thickness. Accordingly, the occlusion of pores having different dimensions (ranging from $\sim 0.01$ to $\sim 100 \mu \mathrm{m}$ ) leads the system from its natural widespread heterogeneity condition (see Figure 4 ) toward a more uniform one, with several pore families of different sizes partially or completely obstructed.

Although the quantitative evaluation of the sorptivity $K$ would not be reliable, since neither a full saturation of the region behind the water front (see Figure 6) nor a uniform pore network during all the imbibing process are satisfied, several considerations from Figure 9 can still be made. 


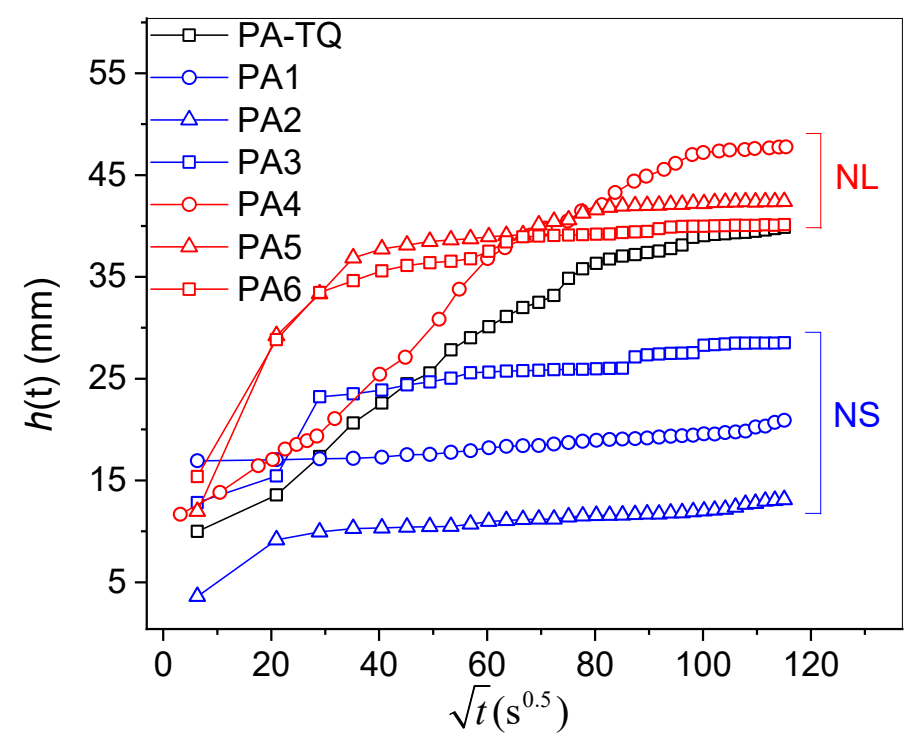

Figure 9. Mean penetration depth of water vs. the square of time for all the investigated PA samples. The experimental evaluation of $h$ was corrected by taking into account the initial thickness of manually added water. Accordingly, all the inflexion point (IP) positions were shifted of 1-3 mm according to the initial thickness of water contained in the aluminum basement, whose contribution can be clearly seen as the highest peaks in the low-millimeter range in Figure 7 for PA2, PA5, PA6, and PA-TQ. In this way, a comparison of all the calculated $h$ values with respect to a common reference can be carried out with high accuracy. In black, the evolution of the water front position for PA-TQ is displayed, whereas the blue and red curves account for the NS- and NL-treated samples, respectively.

In the case of PA5 and PA6, an increased water absorption tendency can be detected with respect to PA-TQ, as reveled by the high rate of variation of $h$ for $\sqrt{t}<\sim 30 \mathrm{~s}^{0.5}$. This means that during the initial stage of water imbibition, the presence of NL seems to enhance the water fluidity inside the porous network of the stone. This can be explained by considering that, close to the impregnated surface, the presence of NL does not occlude pores but rather reinforces them, resulting in a localized enhanced rate of capillary suction. In PA4, this phenomenon is considerably hindered by the enlargement of the already existing microfractures of the stone caused by thermally/RH activated thenardite-mirabilite phase transition. In fact, according to the Young-Laplace equation [61], filling larger air pockets requires more time than filling smaller ones, resulting in a delay in reaching a saturated condition.

Concerning samples PA1, PA2, and PA3, the application of NS slows the water rise, which appears extremely hindered for both short and long exposure times (see blue curves of Figure 9). This occurrence testifies to a massive occlusion of pores preventing the water to flow upward (all three samples remain staked below $20 \mathrm{~mm}$ ), and then reducing the risk of alveolar decohesion, erosion, and the inclusion of damaging substances (with the mean water content also being extremely low; see Figure 7). This confirms, again, that the use of $\mathrm{Nano}^{\mathrm{Estel}}{ }^{\circledR}\left(\right.$ nano- $\left.\mathrm{SiO}_{2}\right)$ as a consolidating agent against artificial weathering is much more convenient with respect to $\mathrm{CaLoSiL}^{\circledR}$ (nanolime). Finally, it is worth noting that changes in the water kinetics between all PA samples can also be ascribed to the different penetration depth of the consolidating product within the porous structure. It is reasonable to assume that, according to the amount of penetrated NS or NL, the water diffusion behavior may also vary, leading to slight alterations of the natural imbibition phenomenon.

\section{Conclusions}

In this work, a neutronographic investigation was carried out on Pietra d'Aspra limestone, a particular type of lithotype extensively used in Baroque buildings of Palermo city (Sicily, Italy). The paper focused on the evaluation of the effectiveness of two different commercially available consolidants, i.e., nanosilica (NS) and nanolime (NL), against naturally occurring degradation 
phenomena (i.e., temperature/RH jumps and salt crystallization), to which buildings and monuments are continuously exposed. The petrographic and physicochemical properties of the investigated limestone were firstly assessed using standard laboratory-based methodologies. Results from petrographic and petrophysical investigations on Pietra d'Aspra biocalcarenites highlighted the heterogeneity of pore network systems in these types of rocks. These features are particularly interesting parameters for interpreting damage processes and their role in the physical and mechanical behavior of the stone. Then, the collected neutron radiographs allowed us to gain insight into the water absorption behavior exhibited by the Pietra d'Aspra stone, revealing a strong relationship between the pore characteristics, in terms of both size and distribution, and the occurring natural water imbibition. In particular, the analysis of the maximum amount of water content and height of the water front revealed a better performance of NS with respect to NL. Furthermore, the effect of several accelerated artificial stimuli on the fluid rises by capillarity was also successfully highlighted through neutron radiography, which, thanks to its high spatial resolution, allowed us to experimentally observe localized water quantities, as well as inner stone alterations (i.e., enlargement of pores following artificially activated phase transitions), otherwise impossible to be revealed. The performed studies of petrophysical properties and capillary imbibition kinetics are indispensable for understanding the degradation mechanisms of Pietra d'Aspra, in order to give an appropriate response for future restoration interventions.

Author Contributions: Conceptualization, V.V., V.C., G.M., M.F.L.R., and D.M.; methodology, F.O. and G.M.; validation, V.V. and M.F.L.R.; formal analysis, L.R., G.P., M.R., and N.R.; investigation, L.R., G.P., V.V., F.O., M.R., and N.R.; data curation, L.R., G.P., M.R., and N.R.; writing-original draft preparation, L.R., G.P., V.V., and M.F.L.R.; writing-review and editing, L.R., G.P., V.V., and M.F.L.R.; visualization, V.V., V.C., G.M., M.F.L.R., and D.M.; supervision, V.V., V.C., G.M., M.F.L.R., and D.M.; project administration, M.F.L.R. All authors have read and agreed to the published version of the manuscript.

Funding: This research received no external funding.

Conflicts of Interest: The authors declare no conflict of interest.

\section{References}

1. Richardson, B. The durability of porous stones. Stone Ind. 1991, 26, 22-25.

2. Hammecker, $\mathrm{C}$. The importance of the petrophysical properties and external factors in the stone decay on monuments. Pure Appl. Geophys. 1995, 145, 337-361. [CrossRef]

3. Leith, S.D.; Reddy, M.M.; Irez, W.F.; Heymans, M.J. Limestone characterization to model damage from acidic precipitation: Effect of pore structure on mass transfer. Environ. Sci. Technol. 1996, 30, 2202-2210. [CrossRef]

4. Mohammad, B.K. The salt durability of some Jordanian limestones as a function of their petrophysical properties. Electron. J. Geotech. Eng. 2003, 8.

5. Benavente, D. Role of pore structure in salt crystallisation in unsaturated porous stone. J. Cryst. Growth. 2004, 260, 532-544. [CrossRef]

6. Bottari, C.; Crisci, G.M.; Crupi, V.; Ignazzitto, V.; La Russa, M.F.; Majolino, D.; Ricca, M.; Rossi, B.; Ruffolo, S.A.; Teixeira, J.; et al. SANS investigation of the salt-crystallization- and surface-treatment-induced degradation on limestones of historic-artistic interest. Appl. Phys. A Mater. Sci. Process. 2016, 122, 721-730. [CrossRef]

7. Rossi Manaresi, R.; Tucci, A. Pore structure and salt crystallization: 'salt decay' of Agrigento, biocalcarenite and 'case hardening' in sandstone. In Proceedings of the La conservazione dei monumenti nel bacino del Mediterraneo: Influenza dell'ambiente costiero e dello spray marino sulla pietra calcarea e sul marmo: Atti del 1o simposio internazionale, Bari, Italy, 7-10 June 1989; pp. 97-100, ISBN 887385060X.

8. Arnold, A.; Zehnder, K. Salt weathering on monuments. In Proceedings of the La conservazione dei monumenti nel bacino del Mediterraneo: Influenza dell'ambiente costiero e dello spray marino sulla pietra calcarea e sul marmo: Atti del 1o simposio internazionale, Bari, Italy, 7-10 June 1989; pp. 31-58.

9. Moropoulou, A.; Theoulakis, P.; Chrysophakis, T. Correlation between stone weathering and environmental factors in marine atmosphere. Atmos. Environ. 1995, 29, 895-903. [CrossRef]

10. Cardell, C.; Delalieux, F.; Roumpopoulos, K.; Moropoulou, A.; Auger, F.; Van Grieken, R. Salt-induced decay in calcareous stone monuments and buildings in a marine environment in SW France. Constr. Build. Mater. 2003, 17, 165-179. [CrossRef] 
11. Pel, L.; Huinink, H.; Kopinga, K.; Van Hees, R.P.J.; Adan, O.C.G. Efflorescence pathway diagram: Understanding salt weathering. Constr. Build. Mater. 2004, 18, 309-313. [CrossRef]

12. Sawdy, A.; Price, C. Salt damage at Cleeve Abbey, England. Part I: A comparison of theoretical predictions and practical observations. J. Cult. Herit. 2005, 6, 125-135. [CrossRef]

13. Moropoulou, A.; Kouloumbi, N.; Haralampopoulos, G.; Konstanti, A.; Michailidis, P. Criteria and methodology for the evaluation of conservation interventions on treated porous stone susceptible to salt decay. Prog. Org. Coat. 2003, 48, 259-270. [CrossRef]

14. López-Acevedo, V.; Viedma, C.; Gonzalez, V.; La Iglesia, A. Salt crystallization in porous construction materials II. Mass transport and crystallization processes. J. Cryst. Growth. 1997, 182, 103-110. [CrossRef]

15. Benavente, D.; Lock, P.; Ángeles García Del Cura, M.; Ordóñez, S. Predicting the capillary imbibition of porous rocks from microstructure. Transp. Porous Media. 2002, 49, 59-76. [CrossRef]

16. Benavente, D.; del Cura, M.A.G.; Fort, R.; Ordónez, S. Durability estimation of porous building stones from pore structure and strength. Eng. Geol. 2004, 74, 113-127. [CrossRef]

17. Karoglou, M.; Moropoulou, A.; Giakoumaki, A.; Krokida, M.K. Capillary rise kinetics of some building materials. J. Colloid Interface Sci. 2005, 284, 260-264. [CrossRef]

18. Barone, G.; Crupi, V.; Longo, F.; Majolino, D.; Mazzoleni, P.; Raneri, S.; Teixeira, J.; Venuti, V. Neutron radiography for the characterization of porous structure in degraded building stones. J. Instrum. 2014, 9, C05024. [CrossRef]

19. Barbera, G.; Barone, G.; Crupi, V.; Longo, F.; Maisano, G.; Majolino, D.; Mazzoleni, P.; Raneri, S.; Teixeira, J.; Venuti, V. A multi-technique approach for the determination of the porous structure of building stone. Eur. J. Mineral. 2014, 26, 189-198. [CrossRef]

20. Crupi, V.; Fazio, B.; Gessini, A.; Kis, Z.; La Russa, M.F.; Majolino, D.; Masciovecchio, C.; Ricca, M.; Rossi, B.; Ruffolo, S.A.; et al. $\mathrm{TiO}_{2}-\mathrm{SiO}_{2}-\mathrm{PDMS}$ nanocomposite coating with self-cleaning effect for stone material: Finding the optimal amount of $\mathrm{TiO}_{2}$. Constr. Build. Mater. 2018, 166, 464-471. [CrossRef]

21. Cid, J.; Alquier, J.F.; Crausse, P. Study of moisture transfer in a deformable porous medium through attenuation of two different energy gamma rays. Rev. Sci. Instrum. 1992, 63, 2057-2064. [CrossRef]

22. Kumaran, M.K.; Bomberg, M. Gamma-Spectrometer for Determination of Density Distribution and Moisture Distribution in Building Materials. In Proceedings of the International Symposium on Moisture and Humidity, Crystal City, VA, USA, 15-19 April 1985; pp. 485-490.

23. Gummerson, R.J.; Hall, C.; Hoff, W.D.; Hawkes, R.; Holland, G.N.; Moore, W.S. Unsaturated water flow within porous materials observed by NMR imaging. Nature 1979, 281, 56-57. [CrossRef]

24. Nemec, T.; Rant, J.; Apih, V. Quantitative measurements of moisture transport in building materials by quasi-real-time neutron radiography. Insight Non-Destructive Test. Cond. Monit. 1999, 41, 449-452.

25. El Abd, A.; Czachor, A.; Milczarek, J. Neutron radiography determination of water diffusivity in fired clay brick. Appl. Radiat. Isot. 2009, 67, 556-559. [CrossRef] [PubMed]

26. Zhao, Y.; Xue, S.; Han, S.; Chen, Z.; Liu, S.; Elsworth, D.; He, L.; Cai, J.; Liu, Y.; Chen, D. Effects of microstructure on water imbibition in sandstones using X-ray computed tomography and neutron radiography. J. Geophys. Res. Solid Earth. 2017, 122, 4963-4981. [CrossRef]

27. Zhao, Y.; Xue, S.; Han, S.; He, L.; Chen, Z. Characterization of unsaturated diffusivity of tight sandstones using neutron radiography. Int. J. Heat Mass Transf. 2018, 124, 693-705. [CrossRef]

28. Zhang, P.; Wittmann, F.H.; Zhao, T.J.; Lehmann, E.H.; Vontobel, P. Neutron radiography, a powerful method to determine time-dependent moisture distributions in concrete. Nucl. Eng. Des. 2011, 241, 4758-4766. [CrossRef]

29. Hall, S.A. Characterization of fluid flow in a shear band in porous rock using neutron radiography. Geophys. Res. Lett. 2013, 40, 2613-2618. [CrossRef]

30. Randazzo, L.; Venuti, V.; Paladini, G.; Crupi, V.; Majolino, D.; Ott, F.; Ricca, M.; Rovella, N.; La Russa, M.F. Evaluating the protecting effects of two consolidants applied on Pietra di Lecce limestone: A neutronographic study. J. Cult. Herit. 2020. [CrossRef]

31. Kang, M.; Perfect, E.; Cheng, C.L.; Bilheux, H.Z.; Gragg, M.; Wright, D.M.; Lamanna, J.M.; Horita, J.; Warren, J.M. Diffusivity and Sorptivity of Berea Sandstone Determined using Neutron Radiography. Vadose Zo. J. 2013, 12. [CrossRef] 
32. Dewanckele, J.; De Kock, T.; Fronteau, G.; Derluyn, H.; Vontobel, P.; Dierick, M.; Van Hoorebeke, L.; Jacobs, P.; Cnudde, $\mathrm{V}$. Neutron radiography and X-ray computed tomography for quantifying weathering and water uptake processes inside porous limestone used as building material. Mater. Charact. 2014, 88, 86-99. [CrossRef]

33. Cheng, C.L.; Perfect, E.; Donnelly, B.; Bilheux, H.Z.; Tremsin, A.S.; McKay, L.D.; DiStefano, V.H.; Cai, J.C.; Santodonato, L.J. Rapid imbibition of water in fractures within unsaturated sedimentary rock. Adv. Water Resour. 2015, 77, 82-89. [CrossRef]

34. Wu, Y.; Zhao, Y.; Li, P. Effect of the heterogeneity on sorptivity in sandstones with high and low permeability in water imbibition process. Processes. 2019, 7, 260. [CrossRef]

35. Sváb, E.; Balaskó, M.; Korösi, F. Dynamic neutron radiography in petrophysical application. Phys. B Condens. Matter. 2000, 276-278, 916-917. [CrossRef]

36. Toropovs, N.; Lo Monte, F.; Wyrzykowski, M.; Weber, B.; Sahmenko, G.; Vontobel, P.; Felicetti, R.; Lura, P. Real-time measurements of temperature, pressure and moisture profiles in High-Performance Concrete exposed to high temperatures during neutron radiography imaging. Cem. Concr. Res. 2015, 68, 166-173. [CrossRef]

37. Zhang, P.; Wittmann, F.H.; Zhao, T.; Lehmann, E.H. Neutron imaging of water penetration into cracked steel reinforced concrete. Phys. B Condens. Matter. 2010, 405, 1866-1871. [CrossRef]

38. Czachor, A.; El-Abd, A.E.L.G.; Milczarek, J.J. Determination of capillary motion of water in bricks using neutron radiography. Acta Phys. Pol. A. 2002, 102, 245-252. [CrossRef]

39. Gruener, S.; Sadjadi, Z.; Hermes, H.E.; Kityk, A.V.; Knorr, K.; Egelhaaf, S.U.; Rieger, H.; Huber, P. Anomalous front broadening during spontaneous imbibition in a matrix with elongated pores. Proc. Natl. Acad. Sci. USA 2012, 109, 10245-10250. [CrossRef]

40. Hall, C.; Tse, T.K.M. Water movement in porous building materials-VII. The sorptivity of mortars. Build. Environ. 1986, 21, 113-118. [CrossRef]

41. Montana, G.; Scaduto, R. La pietra d'Aspra: Storia ed utilizzo; Flaccovio, S.F., Ed.; Flaccovio: Palermo, Italy, 1999; ISBN 8878041610.

42. Alaimo, R.; Montana, G.; Palumbo, B. I materiali lapidei nelle ville barocche di Bagheria. Tipologie di degrado della pietra. TeMa 1994, 2, 44-53.

43. Cipolla, F. Cave di tufi calcarei della Sicilia, età dei giacimenti e metodi di coltivazione. Boll. Ass. Miner. Sicil. 1929, 5, 8-20.

44. Floridia, G.B. Notizie sul sottosuolo di Palermo. Riv. Mineraria Sicil. 1956, 39, 116.

45. La Duca, R. Cave di tufo del Palermitano. Boll. Ord. Ing. Palermo. 1967, 3-4, 7-20.

46. Ruggieri, G. Ostracofauna delle calcareniti bianche quaternarie delle falde a Palermo. Riv. Mineraria Sicil. 1973, 142, 160-170.

47. Salemi Pace, G. Determinazione sperimentale delle costanti specifiche delle pietre da costruzione della Sicilia. Atti del Coll. degli Ing. ed Archit. Palermo. 1880, 4, 99-140.

48. Benavente, D.; García Del Cura, M.A.; Bernabéu, A.; Ordóñez, S. Quantification of salt weathering in porous stones using an experimental continous partial immersion method. Eng. Geol. 2001, 59, 313-325. [CrossRef]

49. Schindelin, J.; Arganda-Carreras, I.; Frise, E.; Kaynig, V.; Longair, M.; Pietzsch, T.; Preibisch, S.; Rueden, C.; Saalfeld, S.; Schmid, B.; et al. Fiji: An open-source platform for biological-image analysis. Nat. Methods. 2012, 9, 676-682. [CrossRef]

50. Kim, F.H.; Penumadu, D.; Hussey, D.S. Water distribution variation in partially saturated granular materials using neutron imaging. J. Geotech. Geoenvironmental Eng. 2011, 138, 147-154. [CrossRef]

51. Dunham, R.J. Classification of Carbonate Rocks According to Depositional Textures. Amer. Ass. Pet. Geol. 1962, 108-121.

52. Folk, R.L. Spectral subdivision of limestone types. Bull. Am. Assoc. Pet. Geol. 1962, 1, 62-84.

53. Alaimo, R.; Montana, G.; Polizzi, G. Caratteristiche mineralogico-petrografiche delle calcareniti in opera nei complessi monumentali della Sicilia Occidentale. Miner. Petrogr. Acta. 1998, 41, 243-266.

54. Perfect, E.; Cheng, C.L.; Kang, M.; Bilheux, H.Z.; Lamanna, J.M.; Gragg, M.J.; Wright, D.M. Neutron imaging of hydrogen-rich fluids in geomaterials and engineered porous media: A review. Earth Sci. Rev. 2014, 129, 120-135. [CrossRef]

55. Steiger, M.; Asmussen, S. Crystallization of sodium sulfate phases in porous materials: The phase diagram Na2SO4-H2O and the generation of stress. Geochim. Cosmochim. Acta 2008, 72, 4291-4306. [CrossRef] 
56. Yang, L.; Gao, D.; Zhang, Y.; Tang, J.; Li, Y. Relationship between sorptivity and capillary coefficient for water absorption of cement-based materials: Theory analysis and experiment. R. Soc. Open Sci. 2019, 6, 190112. [CrossRef]

57. Hanžič, L.; Ilić, R. Relationship between liquid sorptivity and capillarity in concrete. Cem. Concr. Res. 2003, 33, 1385-1388. [CrossRef]

58. Zhang, P.; Wittmann, F.H.; Zhao, T.J.; Lehmann, E. Observation and Quantification of Water Penetration into Frost Damaged Concrete by Neutron Radiography / Beobachtung und quantitative Bestimmung der Wasseraufnahme von Frost geschädigtem Beton mit Hilfe der Neutronenradiographie. Restor. Build. Monum. 2014, 16, 195-210. [CrossRef]

59. Lucas, R. Ueber das Zeitgesetz des kapillaren Aufstiegs von Flüssigkeiten. Kolloid-Zeitschrift. 1918, 23 , 15-22. [CrossRef]

60. Washburn, E.W. The dynamics of capillary flow. Phys. Rev. 1921, 17, 273-283. [CrossRef]

61. Lucero, C.L.; Bentz, D.P.; Hussey, D.S.; Jacobson, D.L.; Weiss, W.J. Using Neutron Radiography to Quantify Water Transport and the Degree of Saturation in Entrained Air Cement Based Mortar. Phys. Procedia 2015, 69, 542-550. [CrossRef]

(C) 2020 by the authors. Licensee MDPI, Basel, Switzerland. This article is an open access article distributed under the terms and conditions of the Creative Commons Attribution (CC BY) license (http://creativecommons.org/licenses/by/4.0/). 